\title{
Lifetime Follow-up Care After Childhood Cancer
}

\author{
Richard I. Haddy, MD, and Theresa B. Haddy, MD
}

Cancers that occur during childhood and adolescence (ages 0 to 19 years) are very responsive to treatment, with a current overall cure rate of better than $80 \%$. However, approximately $75 \%$ of childhood cancer survivors develop late effects, including problems with growth and development, vital organ function, reproduction, and psychological health, as well as serious complications of secondary neoplasms and recurrence. The primary physician should continue some level of involvement during all phases of patient care and pay special attention to possible late effects during the follow-up phase. (J Am Board Fam Med 2010;23:647-654.)

Keywords: Cancer, Child, Adolescent, Treatment, Late Effects, Physician's Role, Cancer Survivorship

Large numbers of children and adolescents are now being cured of cancer, but the therapy they have received places them at risk for future adverse consequences. Primary care physicians should remain involved with their patients during diagnosis, treatment, follow-up, and, when treatment fails, palliative care. Although specific treatment of the malignant diseases of children and adolescents is best provided by specialists trained in pediatrics and pediatric hematology/oncology, involvement of the primary care physician is especially important when specific cancer treatment is completed and the patients move on to further schooling and work. Lifelong surveillance and intervention are essential.

\section{Scope of the Problem}

According to the Centers for Disease Control and Prevention, the incidence of cancer among children

This article was externally peer reviewed.

Submitted 12 February 2010; revised 22 May 2010; accepted 27 May 2010.

From from the Department of Family and Geriatric Medicine, University of Louisville, Louisville, KY (RIH); and the Department of Pediatric Hematology-Oncology, Children's National Medical Center, Washington, DC (TBH).

Funding: none.

Conflict of interest: none declared.

Corresponding author: Theresa B. Haddy, MD, 211 Second Street NW \#1607, Rochester, MN 55901-2896 (E-mail: TBHaddy@aol.com).

\footnotetext{
See Related Commentary on Page 564.
}

(0-14 years old) and adolescents (15-19 years old) is increasing. ${ }^{1}$ At the same time, the death rate from childhood cancer is decreasing. ${ }^{1}$

Incidence rates for all childhood cancers increased by $0.6 \%$ per year during 1975 to $2002 .^{2}$ The incidence of cancer for children and adolescents 0 to 19 years old —-for all sites and all racesincreased from 15.1 per 100,000 per year in 2002 to 16.6 per 100,000 per year in 2006 (Table 1). Cancer is the fourth most common cause of death among individuals 1 to 19 years old in the United States, after unintentional injury, homicide, and suicide. ${ }^{3,4}$

Death rates from all causes decreased significantly during 1990 to 2004 among both sexes, both age groups, Hispanics, non-Hispanics, all races (except American Indians and Alaska Natives), and all US census regions. ${ }^{1}$ The death rate from cancer for children and adolescents 0 to 19 years old for all sites and all races decreased from 5.1 per 100,000 in 1975 to 2.5 per 100,000 in 2006 (Table 2).

The trend in decreasing cancer mortality (Table 3) can be attributed to improved cancer treatment. The reasons for the increased incidence of cancer are not so easy to determine because the causes of childhood cancer are largely unknown and differ from the causes of adult cancer. ${ }^{5}$ Genetic predisposition is a known factor. ${ }^{6}$ Increased exposure to radiation from radiology tests, ${ }^{7-9}$ including plain radiography and computerized tomography, ${ }^{10-12}$ and from communication systems ${ }^{13}$ can contribute to the problem. Chemicals in food could have adverse effects. It has also been suggested that better diagnostic methods or changes in reporting might 
Table 1. Surveillance Epidemiology and End Results Age-Adjusted Childhood Cancer Incidence* among the US Population for All Races and Sexes, 2002 to 2006 by Primary Cancer Site ${ }^{3}$

\begin{tabular}{lcc}
\hline & \multicolumn{2}{c}{ Incidence by Age } \\
\cline { 2 - 3 } & $0-14$ Years & $0-19$ Years \\
\hline All sites, all races & 15.1 & 16.6 \\
Leukemia & 5.0 & 4.5 \\
Acute lymphoblastic leukemia & 4.0 & 3.4 \\
Brain and nervous system & 3.2 & 2.9 \\
Hodgkin lymphoma & 0.6 & 1.2 \\
Soft tissue & 1.0 & 1.1 \\
Non-Hodgkin lymphoma & 0.9 & 1.1 \\
Bone and joint & 0.7 & 0.9 \\
Kidney and renal pelvis & 0.8 & 0.6 \\
\hline
\end{tabular}

*Rates are per 100,000 and are age-adjusted to the 2000 US population.

help to explain the increased incidence of childhood cancer. ${ }^{5}$

\section{Classification of Childhood Cancers}

Although most adult solid cancers are carcinomas and traditionally have been classified according to primary site, childhood cancers are histologically more diverse. According to the International Classification of Diseases, childhood cancers are subdivided into 10 groups and listed according to morphology rather than frequency, ${ }^{14}$ including nonmalignant intracranial and intraspinal tumors (Table 4).

\section{Treatment}

The primary modes of therapy for childhood and adolescent cancer are surgery, radiation, chemotherapy, and transplantation. Surgery has a role in biopsy (pathologic diagnosis); staging; and, when possible, removal of the tumor or affected organ. Because of possible microscopic residual disease or distant micrometastases, adjuvant radiation and chemotherapy are usually added to the treatment regimen.

Surgical removal of the affected kidney (nephrectomy) remains the primary treatment for Wilms tumor (nephroblastoma), the second most successfully managed malignancy of childhood, with a cure rate of $91.2 \%$ (Table 3). Studies by the National Wilms Tumor Study Group have shown radiation to be unnecessary if the tumor can be completely resected. ${ }^{15}$ Bone tumors are treated with amputation or limb-sparing surgery; the limbsalvaging procedure results in somewhat better function than amputation. ${ }^{16,17}$ Splenectomy, which carries a lifetime risk for sepsis, is no longer a routine staging procedure for Hodgkin lymphoma. Diagnostic imaging studies provide more accurate information about the abdominal organs and lymph nodes. Patients who are asplenic, however, must be protected against bacterial infections with immunizations and chemoprophylaxis, along with early evaluation and treatment for febrile illnesses.

Radiotherapy is an important treatment modality for a number of childhood cancers, but children and adolescents are especially sensitive and susceptible to side effects because their tissues are still growing and developing. Radiation, along with additional chemotherapy, is highly effective against Hodgkin lymphoma, which has the highest cure rate among childhood cancers at $95.5 \%$ (Table 3). Unfortunately, radiation to the mantle area or chest can place the patient at risk for thyroid disorders, pulmonary complications, and lung and breast cancers. ${ }^{18,19}$ Radiotherapy is standard treatment for some brain tumors, as well as for some rhabdomyosarcomas and other soft tissue sarcomas of the head and neck. Radiation of the brain introduces a number of further serious neurocognitive late effects. Melanoma and other skin cancers can develop in the involved field after radiation to any area of the body. ${ }^{20}$

Table 2. Surveillance Epidemiology and End Results Age-Adjusted Childhood Cancer Death Rates* among the US Population for All Races and Sexes, 1975 and 2006 by Primary Cancer Site

\begin{tabular}{lcccccc}
\hline & \multicolumn{4}{c}{ Death Rates by Age } \\
\cline { 2 - 3 } \cline { 6 - 7 } & \multicolumn{2}{c}{$0-14$ Years } & & $0-19$ Years \\
\cline { 2 - 3 } All sites, all races & 1975 & 2006 & & 1975 & 2006 \\
Brain and nervous system & 4.9 & 2.2 & & 5.1 & 2.5 \\
Leukemia & 1.0 & 0.6 & & 0.9 & 0.7 \\
Acute lymphoblastic leukemia & 1.2 & 0.3 & & 1.0 & 0.3 \\
Soft tissue & 0.1 & 0.1 & & 0.2 & 0.2 \\
Kidney and renal pelvis & 0.2 & 0.1 & & 0.1 & 0.1 \\
Non-Hodgkin lymphoma & 0.4 & 0.1 & & 0.4 & 0.1 \\
Hodgkin lymphoma & 0.0 & - & 0.1 & 0.0 \\
\hline
\end{tabular}

${ }^{*}$ Rates are per 100,000 and are age-adjusted to the 2000 US population. 
Table 3. Surveillance Epidemiology and End Results 5-Year Survival Rates* among the US Population, 1975 to 1977 and 1999 to 2005, by Selected Primary Cancer Site

\begin{tabular}{lcccc}
\hline & \multicolumn{3}{c}{ Survival Rates by Age (\%) } \\
\cline { 2 - 3 } & \multicolumn{2}{c}{ 0-14 Years } & \multicolumn{2}{c}{ 0-19 Years } \\
\cline { 2 - 4 } & $1975-1977$ & $1999-2005$ & $1975-1977$ & $1999-2005$ \\
\hline \multirow{2}{*}{ All sites, all races } & 58.1 & 81.3 & 61.6 & 81.0 \\
Hodgkin lymphoma & 80.5 & 95.4 & 86.0 & 95.5 \\
Wilms tumor & 73.1 & 91.2 & 72.6 & 91.2 \\
Acute lymphoblastic leukemia & 57.6 & 89.0 & 54.1 & 85.1 \\
Non-Hodgkin lymphoma & 43.5 & 86.3 & 44.6 & 84.4 \\
Leukemia & 50.4 & 83.6 & 45.5 & 78.7 \\
Soft tissue & 61.0 & 81.0 & 65.2 & 75.6 \\
Brain and central nervous system & 56.9 & 73.8 & 58.8 & 74.2 \\
Neuroblastoma & 52.4 & 74.2 & 52.7 & 73.9 \\
Bone and joint & 49.9 & 71.8 & 50.4 & 68.5 \\
Acute myeloid leukemia & 18.8 & 60.2 & 18.7 & 55.0 \\
\hline
\end{tabular}

*Rates are based on follow-up of patients into 2006.

Chemotherapy is included in the treatment of most forms of childhood cancer to deal with residual disease and distant micrometastases, but chemotherapy alone is usually adequate for control of leukemias. Chemotherapy for acute lymphoblastic leukemia (ALL) has undergone improvement and refinement so that the 5 -year survival rate is now $81.3 \%$ for children ages 0 to 14 and $85.1 \%$ for children and adolescents ages 0 to 19 years (Table 3). The first chemotherapeutic agent to achieve a temporary remission of ALL in 1948 was aminopterin, a relative of methotrexate, followed by

Table 4. Childhood Cancers in Diagnostic Groups According to the International Classification of Childhood Cancer ${ }^{14}$

\begin{tabular}{ll}
\hline Classification & \multicolumn{1}{c}{ Type(s) of Cancer } \\
\hline I & $\begin{array}{c}\text { Leukemias, myeloproliferative, and } \\
\text { myelodysplastic diseases } \\
\text { Lymphomas and reticuloendothelial } \\
\text { II }\end{array}$ \\
III & $\begin{array}{c}\text { Ceoplasms } \\
\text { intral nervous system and other }\end{array}$ \\
IV & Neuroblastoma and other peripheral \\
& nervous cell tumors \\
V & Retinoblastoma \\
VI & Renal tumors \\
VII & Hepatic tumors \\
VIII & Malignant bone tumors \\
IX & Soft tissue and other extraosseous sarcomas \\
X & Germ cell tumors, trophoblastic tumors, \\
& and neoplasms of gonads \\
\hline
\end{tabular}

6-mercaptopurine in 1953, 1-asparaginase in 1961, vincristine in 1962, and subsequently by corticosteroids and other agents, ${ }^{21}$ including epipodophyllotoxins and heavy metals. More recently, monoclonal antibodies have become used as anticancer therapy. ${ }^{22,23}$ Further refinements of the administration of chemotherapy included continuous combination therapy and intrathecal chemotherapy against leukemic cell sanctuaries in the central nervous system and meninges. The establishment of large, national, multi-institutional, cooperative study groups funded by the National Institutes of Health for the study of childhood malignancies helped to assess the effectiveness and toxicities of treatment regimens, even for cancers that were uncommon or rare. ${ }^{21}$ The cooperative study groups in the United States have combined to become the present Children's Oncology Group.

Bone marrow transplantation and peripheral blood stem cell transplantation is accomplished by destruction of the cells of the marrow and replacement with the donor's own stem cells (autologous transplant), stem cells from an identical twin (syngeneic transplant), or stem cells from a matched donor, usually a close relative (allogeneic transplant). Umbilical cords are another source of stem cells. Patients with acute myeloid leukemia are the most frequent candidates for myeloblative stem cell transplant. ${ }^{24}$ Major transplant toxicities include graft rejection, graft-versus-host disease, and the problems that go along with the necessary pro- 
longed immunosuppression, such as septicemia and other infections.

Many useful current publications concerning childhood cancer survivors are from a large epidemiologic study, the Childhood Cancer Survivors Study, based at the University of Minnesota Cancer Center. Information from the Childhood Cancer Survivors Study can be accessed through the National Institutes of Health website ${ }^{25}$ or by calling 1-800-4-CANCER. Another useful resource is the "Quick Reference for Pediatric Oncology Clinicians: The Psychiatric and Psychological Dimensions of Pediatric Cancer Symptom Management" published through the American Psychosocial Oncology Society. ${ }^{26}$

\section{Late Effects}

At present, treatment results in a cure rate of $\geq 80 \%$ for childhood cancer ${ }^{27}$; however, a high rate of adverse events can be expected among survivors. Reports in the literature indicate that approximately $75 \%$ of survivors have one or more late effects $^{28-30}$; the complications of therapy may be categorized as shown in Table 5. The majority of late effects result from treatment-related toxicity or from complications of the original cancer. ${ }^{27,31} \mathrm{Ad}-$ ditional problems include comorbidities that might be worse than otherwise expected and health problems that occur with aging. ${ }^{32}$

The most common late effects are those of growth and development, including linear growth velocity, intellectual development, and sexual maturation (Table 5). Damage to the hypothalamus from cranial radiation ${ }^{33,34}$ or from chemotherapy alone $\mathrm{e}^{35}$ can cause decreased production of growth hormones and growth failure. Learning problems and hyperactivity can also be attributed to cranial radiation. ${ }^{36,37}$ Delayed sexual maturation can be

Table 5. Assessment of Late Effects*

\begin{tabular}{|c|c|c|}
\hline Complication & Surveillance & Treatment Modality \\
\hline Growth failure & History/examination & $\begin{array}{l}\text { Chemotherapy } \\
\text { Cranial radiation }\end{array}$ \\
\hline Intellectual function & Psychiatric test & Cranial radiation \\
\hline Neurological toxicity & Neurologic examination & $\begin{array}{l}\text { Cranial radiation } \\
\text { Vincristine }\end{array}$ \\
\hline Dental & $\begin{array}{l}\text { Examination } \\
\text { Cleaning }\end{array}$ & $\begin{array}{l}\text { Chemotherapy } \\
\text { Cranial radiation }\end{array}$ \\
\hline Male infertility & $\begin{array}{l}\text { LH, FSH } \\
\text { Testosterone } \\
\text { Sperm count }\end{array}$ & $\begin{array}{l}\text { Abdominal/pelvic radiation } \\
\text { Cyclophosphamide } \\
\text { Doxorubicin/daunomycin }\end{array}$ \\
\hline Female infertility & $\begin{array}{l}\text { LH, FSH } \\
\text { Estradial }\end{array}$ & $\begin{array}{l}\text { Abdominal/pelvic radiation } \\
\text { Cyclophosphamide } \\
\text { Doxorubicin/daunomycin }\end{array}$ \\
\hline Cardiac & ECG, echocardiogram & Doxorubicin/daunomycin \\
\hline Bladder & Urinalysis & $\begin{array}{l}\text { Cyclophosphamide } \\
\text { Ifosphamide }\end{array}$ \\
\hline Lung & Chest radiograph & Buslfan \\
\hline Liver & LFTs & Methotrexate \\
\hline Bone & DEXA scan & $\begin{array}{l}\text { Prednisone/dexamethasone } \\
\text { Methotrexate }\end{array}$ \\
\hline Eye (cataracts) & Visual acuity & Prednisone/dexamethasone \\
\hline Ear (hearing) & Audiogram & Cisplatinum/carboplatinum \\
\hline Second neoplasms & $\begin{array}{l}\text { Examination } \\
\text { Blood count } \\
\text { Urinalysis }\end{array}$ & $\begin{array}{l}\text { Radiation } \\
\text { Cyclophosphamide } \\
\text { Doxorubicin/daunomycin }\end{array}$ \\
\hline Recurrence & History/examination & \\
\hline
\end{tabular}

*As recommended in "Long-Term Guidelines for Survivors of Childhood, Adolescent, and Young Adult Cancers," published by the Children's Oncology Group in 2008 (www.survivorshipguidelines.org).

LH, luteinizing hormone; FSH, follicle-stimulating hormone; ECG, electrocardiogram; LFT, liver function test; DEXA, dual energy $\mathrm{x}$-ray absorptiometry. 
caused by cranial radiation, abdominal and pelvic radiation, and alkylating agents. Although prophylactic cranial radiation has largely been supplanted by intrathecal chemotherapy, it is still given to patients with T-cell ALL and those with a central nervous system relapse of pre-B-cell leukemia.

Obesity, which is increasing in general among children and adolescents in the United States, ${ }^{38}$ is increasing among childhood cancer survivors as well and can be related to cranial radiation, especially in women who were treated at an early age. ${ }^{39,40}$ There is evidence that a genetic variation in the leptin receptor gene can influence obesity among survivors, ${ }^{41}$ and it has been suggested that adipose dysfunction could play a role in cancer pathogenesis and progression. ${ }^{42}$ It is also important to note that a significant proportion of childhood cancer survivors are underweight as adults. ${ }^{40,43}$

Failure to reach peak bone mass, with 2 important resulting problems (osteoporosis/osteopenia and osteonecrosis), is not uncommon among survivors and is now beginning to receive appropriate attention. ${ }^{44,45}$ Possible complications of bone mineral density deficits include fractures, kyphosis, lordosis, scoliosis, abnormal gait, and bone or muscle pain. $^{46,47}$

Cardiovascular problems, the most common of the complications that affect vital organs (Table 5), can occur early or late and are seen especially among individuals who have received anthracyclines. ${ }^{48-51}$ Even survivors who were treated with low doses should receive, in addition to routine cardiac screening, periodic echocardiography and measurement of natriuretic peptides. ${ }^{48,50}$ Hypertension, which is not uncommon among survivors, requires attention and early intervention as a risk factor for atherosclerotic cardiovascular disease. ${ }^{52}$ Other effects on vital organs that require attention include respiratory symptoms, changes in liver function test values, hyperglycemia, hypothyroidism, and altered renal function.

Women who have survived childhood or adolescent cancer are less likely to become pregnant than their siblings. ${ }^{53,54}$ Hypothalamic or pituitary radiation and ovarian or uterine radiation significantly reduce the likelihood of female survivors to become pregnant, as does chemotherapy with alkylating agents, because of altered frequency of ovulation. ${ }^{53,54}$ Infants born to female survivors do not have an increased risk of malformations but often have early delivery and low birth weight. ${ }^{55}$ The female partners of male cancer survivors are not likely to have complicated pregnancies except for the possibility of preeclampsia and low birth weight. ${ }^{56}$ Before the start of therapy, pediatric and adolescent cancer victims should be informed of the possible effects of treatment on fertility and of options for fertility preservation, such as ovarian transposition before pelvic radiation, sperm and embryo cryopreservation, and egg freezing. ${ }^{57,58}$ However, delaying the start of treatment for these procedures must be given serious consideration, especially in the case of advanced cancers.

The most serious late effects to watch for are recurrences ${ }^{59}$ and second cancers ${ }^{60}$; second malignancies are the leading cause of death among longterm ( $\geq 15$ years) survivors. ${ }^{61}$ Second cancers can be classified into 2 groups: (1) myelodysplasia and AML related to chemotherapy and (2) solid second malignancies related to radiation. ${ }^{62}$ Several large, recent studies have shown that the excess risk for survivors continues for at least 3 decades. ${ }^{63-65}$ It is important to note that some second cancers can be treated with good results, ${ }^{66}$ but others, especially those of the brain, are not curable.

Although the majority of childhood cancer survivors do not exhibit adverse symptoms concerning their psychological health and well-being, they are significantly more likely to report depression and symptoms of somatic distress than their siblings. ${ }^{36}$ A substantial subset of survivors has reported symptoms of posttraumatic stress disorder compared with the general population. ${ }^{67}$ Furthermore, adult survivors of childhood cancer, especially those with physical health problems, are at increased risk for suicide ideation. ${ }^{68}$ Regarding employment, young adult survivors report higher rates of unemployment, underemployment, and job discrimination than their siblings. ${ }^{69}$ They are less likely to marry than their sibling controls, but their divorce pattern is similar to that of their peers ${ }^{70}$; not being married is likely to be associated with short stature, poor physical findings, and cognitive problems. ${ }^{70}$

\section{Role of the Primary Physician}

Although specific cancer treatment is best provided by specialists trained in pediatric hematology/oncology, it is essential that primary physicians remain involved in the care of children and adolescents who have malignant diseases. ${ }^{71}$ The important phases of care include helping to make 
the original diagnosis (ie, being alert for adverse symptoms that might call attention to diagnosis of childhood cancer or the onset of late effects); serving as a guide for referrals for cancer diagnosis and treatment as well as diagnosis and treatment of late effects; providing supportive emotional care to the patient and family through often stressful treatment; remaining alert to possible late effects during careful lifetime follow-up and continuing routine day-to-day medical care as needed; and, finally, assisting with end-of-life decisions and palliative care if treatment is unsuccessful.

The diagnosis is made during phase one. The early signs and symptoms of cancer are often not specific and can include fever, lethargy, weight loss, general malaise, and pain, which can be attributed to a benign cause. These complaints must be taken seriously, and they should be carefully evaluated if they persist to avoid a delayed diagnosis. The primary physician usually sends the patient for specific testing and, with either a presumptive or a definitive diagnosis, refers the family for specialty care.

The primary physician should remain involved and informed during the second phase, during which definitive treatment is conducted, to offer emotional support to the patient and family. This should include ensuring that proper attention is given to health concerns and routine medical care for siblings and other family members. If travel to a tertiary care center is difficult, the community care provider could administer and monitor certain treatments. At some point the parents need to make an important decision about which treatment plan to accept or whether or not to continue treatment. As a friend and confidant, the primary physician would be in a position to discuss alternatives and to support whatever decision is made.

The third phase follows after treatment is completed. Most specialists offer continuing care in follow-up clinics or late effects clinics, and follow-up should be lifelong. Because the primary care physician continues to be involved with dayto-day problems such as minor illnesses, playground or sports injuries, school physical examinations, and routine immunizations, he or she is likely to be the first observer of any untoward symptoms or signs. Knowing that late effects are frequent and can be expected in $\geq 70 \%$ of survivors $^{27}$ will allow the primary physician to recognize and deal promptly with problems when they occur.
A fourth and final phase occurs if treatment fails and death is inevitable. Whether the patient and his or her family choose to receive end-of-life care in the hospital, hospice, or at home, the primary physician should remain available to the patient and family.

\section{Conclusion}

It is important for primary care physicians, including family practitioners, pediatricians, and internists, to continue their involvement with child and adolescent cancer patients and their families throughout all phases of management. They should be especially alert to the possibility of late effects that may occur during the follow-up period.

\section{References}

1. Centers for Disease Control and Prevention (CDC). Trends in childhood cancer mortality-United States, 1990-2004. MMWR Morb Mortal Wkly Rep 2007; 56:1257-61.

2. Ward EM, Thun MJ, Hannan LM, Jemal A. Interpreting cancer trends. Ann N Y Acad Sci 2006;1076: 29-53.

3. National Cancer Institute. Surveillance epidemiology and end results. Previous version: SEER cancer statistics review, 1975-2005 (accessible version). Available at http://seer.cancer.gov/csr/1975_2005/ accessible_contents.html. Accessed 18 July 2010.

4. Jemal A, Siegel R, Ward E, Hao Y, Xu J, Thun MJ. Cancer statistics, 2009. CA Cancer J Clin 2009;59: 225-49.

5. Linet MS, Ries LAG, Smith MA, Tarone RE, Devesa SS. Cancer surveillance series: recent trends in childhood cancer incidence and mortality in the United States. J Natl Cancer Inst 1999;91:1051-8.

6. Fröhling S, Döhner H. Chromosomal abnormalities in cancer. N Engl J Med 2008;359:722-34.

7. Fazel R, Krumholz HM, Wang Y, et al. Exposure to low-dose ionizing radiation from medical imaging procedures. N Engl J Med 2009;361:849-57.

8. Lauer MS. Elements of danger-the case of medical imaging. N Eng J Med 2009;361:841-3.

9. Becker GJ, Bosma J, Hendee W. Radiation exposure from medical imaging procedures [letter]. N Engl J Med 2009;361:2289-90; author reply 2291-2.

10. Redberg RF. Cancer risks and radiation exposure from computed tomographic scans. Arch Intern Med 2009; 169:2049-50.

11. de González AB, Mahesh M, Kim K-P, et al. Projected risks from computed tomographic scans performed in the United States in 2007. Arch Intern Med 2009;169:2071-7.

12. Smith-Bindman R, Lipson J, Marcus R, et al. Radiation dose associated with common computed to- 
mography examinations and the associated lifetime attributable risk of cancer. Arch Intern Med 2009; 169:2078-86.

13. Myung SK, Ju W, McDonnell DD, et al. Mobile phone use and risk of tumors: a meta-analysis. J Clin Oncol 2009;27:5565-72.

14. Steliarova-Foucher E, Siller C, Lacour B, Kaatsch P. International Classification of Childhood Cancer, third edition. Cancer 2005;103:1457-67.

15. D'Angio GJ, Breslow N, Beckwith JB, et al. Treatment of Wilms' tumor. Results of the Third National Wilms' Tumor Study. Cancer 1989;64:349-60.

16. Nagarajan R, Neglia JP, Clohisy DR, Robison L. Limb salvage and amputation in survivors of pediatric lower-extremity bone tumors: what are the longterm implications? J Clin Oncol 2002;20:4493-501.

17. Eiser C, Darlington AS, Stride CB, Grimer R. Quality of life implications as a consequence of surgery: limb salvage, primary and secondary amputation. Sarcoma 2001;5:189-95.

18. Oeffinger KC, Ford JS, Moskowitz CS, et al. Breast cancer surveillance practices among women previously treated with chest radiation for a childhood cancer. JAMA 2009;301:404-14.

19. Taylor AJ, Taylor RE. Surveillance for breast cancer after childhood cancer. JAMA 2009;301:435-6.

20. Perkins JL, Liu Y, Mitby PA, et al. Nonmelanoma skin cancer in survivors of childhood and adolescent cancer: a report from the Childhood Cancer Survivor Study. J Clin Oncol 2005;23:3733-41.

21. Pearson HA. History of pediatric hematology oncology. Pediatr Res 2002;52:979-92.

22. Dillman RO. Negative outcomes associated with adding anti-epidermal growth factor receptor (EGFR) monoclonal antibodies to chemotherapybevacizumab combination therapy in patients with metastatic colorectal cancer. Am J Hematol Oncol 2009;8:425-8.

23. Oldham RK, Dillman RO. Monoclonal antibodies in cancer therapy: 25 years of progress. J Clin Oncol 2008;26:1774-7.

24. Lane AA, Chen Y-B. Acute myeloid leukemia in first complete remission: how do we select patients for allogeneic stem cell transplantation? Am J Hematol Oncol 2009;8:508-11.

25. National Cancer Institute. The Childhood Cancer Survivor Study: an overview. 2009. Available at http://www.cancer.gov/cancertopics/coping/ccss. Accessed 24 July 2010.

26. Wiener LS, Pao M, Kazak AE, Kupst MJ, Farkas Patenaude A, Holland JC, editors. Quick reference for pediatric oncology clinicians: the psychiatric and psychological dimensions of pediatric cancer symptom management. Charlottesville, VA: IPOS Press; 2009.

27. Oeffinger KC, Robison LL. Childhood cancer survivors, late effects, and a new model for understanding survivorship. JAMA 2007;297:2762-4.
28. Haddy TB, Mosher RB, Reaman GH. Late effects in long-term survivors after treatment for childhood acute leukemia. Clin Pediatr 2009;48:601-8.

29. Cardous-Ubbink MC, Heinen RC, Langeveld NE, et al. Long-term cause-specific mortality among five-year survivors of childhood cancer. Pediatr Blood Cancer 2004;42:563-73.

30. Meadows AT. Cancer survivors: childhood and beyond. J Pediatr Hematol Oncol 2007;29:S13-4.

31. Geenen MM, Cardous-Ubbink MC, Kremer LCM, et al. Medical assessment of adverse health outcomes in long-term survivors of childhood cancer. JAMA 2007;297:2705-15.

32. Oeffinger KC, Mertens AC, Sklar CA, et al. Chronic health conditions in adult survivors of childhood cancer. N Engl J Med 2006;355:1572-82.

33. Adan L, Trivin C, Sainte-Rose C, Zucker JM, Hartmann O, Brauner R. GH deficiency caused by cranial irradiation during childhood: factors and markers in young adults. J Clin Endocrinol Metab 2001; 86:5245-51.

34. Müller HL, Klinkhammer-Schalke M, Kühl J. Final height and weight of long-term survivors of childhood malignancies. Exp Clin Endocrinol Diabetes 1998;106:135-9.

35. Haddy TB, Mosher RB, Nunez SB, Reaman GH. Growth hormone deficiency after chemotherapy for acute lymphoblastic leukemia in children who have not received cranial radiation. Pediatr Blood Cancer 2006;46:258-61.

36. Zebrack BJ, Zeltzer LK, Whitton J, et al. Psychological outcomes in long-term survivors of childhood leukemia. Hodgkin's disease, and non-Hodgkin's lymphoma: a report from the Childhood Cancer Survivor Study. Pediatrics 2002;110:42-52.

37. Harila-Saari AH, Lähteenmäki PM, Pukkala E, Kyyrönen $\mathrm{P}$, Lanning $M$, Sankila R. Scholastic achievements of childhood leukemia patients: a nationwide, register-based study. J Clin Oncol 2007;25:3518-24.

38. Ogden CL, Carroll MD, Flegal KM. High body mass index for age among US children and adolescents, 2003-2006. JAMA 2008;299:2401-5.

39. Oeffinger KC, Mertens AC, Sklar CA, et al. Obesity in adult survivors of childhood acute lymphoblastic leukemia: a report from the Childhood Cancer Survivor Study. J Clin Oncol 2003;21:1359-65.

40. Meacham LR, Gurney JG, Mertens AC, et al. Body mass index in long-term adult survivors of childhood cancer: a report of the Childhood Cancer Survivor Study. Cancer 2005;103:1730-9.

41. Ross JA, Oeffinger KC, Davies SM, et al. Genetic variation in the leptin receptor gene and obesity in survivors of childhood acute lymphoblastic leukemia: a report from the Childhood Cancer Survivor Study. J Clin Oncol 2004;22:3558-62.

42. van Kruijsdijk RCM, van der Wall E, Vissseren FLJ. Obesity and cancer: the role of dysfunctional adipose 
tissue. Cancer Epidemiol Biomarkers Prev 2009;18: 2569-78.

43. Ross JA. Genetic susceptibility and body mass in childhood cancer survivors. Pediatr Blood Cancer 2007;48:731-5.

44. Kaste SC. Skeletal toxicities of treatment in children with cancer. Pediatr Blood Cancer 2008;50(2 Suppl): 469-73.

45. Wasilewski-Masker K, Kaste SC, Hudson MM, Esiashvili N, Mattano LA, Meacham LR. Bone mineral density deficits in survivors of childhood cancer: long-term follow-up guidelines and review of the literature. Pediatrics 2008;121:e705-13.

46. Thomas IH, Donohue JE, Ness KK, Dengel DR, Baker KS, Gurney JG. Bone mineral density in young adult survivors of acute lymphoblastic leukemia. Cancer 2008;113:3248-56.

47. Haddy TB, Mosher RB, Reaman GH. Osteoporosis in survivors of acute lympoblastic leukemia. Oncologist 2001;6:278-85.

48. Lipshultz SE, Lipsitz SR, Sallan SE, et al. Chronic progressive cardiac dysfunction years after doxorubicin therapy for childhood acute lymphoblastic leukemia. J Clin Oncol 2005;23:2629-36.

49. Creutzig U, Diekamp S, Zimmermann M, Reinhardt D. Longitudinal evaluation of early and late anthracycline cardiotoxicity in children with AML. Pediatr Blood Cancer 2007;48:651-62.

50. Rathe M, Carlsen NLT, Oxhøj H. Late cardiac effects of anthracycline containing therapy for childhood acute lymphoblastic leukemia. Pediatr Blood Cancer 2007;48:663-7.

51. Poutanen T, Tikanoja T, Riikonen P, Silvast A, Perkkiö M. Long-term prospective follow-up study of cardiac function after cardiotoxic therapy for malignancy in children. J Clin Oncol 2003;21:2349-56.

52. Haddy TB, Mosher RB, Reaman GH. Hypertension and prehypertension in long-term survivors of childhood and adolescent cancer. Pediatr Blood Cancer 2007;49:79-83.

53. Green DM, Kawashima T, Stovall M, et al. Fertility of female survivors of childhood cancer: a report from the Childhood Cancer Survivor Study. J Clin Oncol 2009;27:2677-85.

54. Green DM. Fertility of women who survive childhood cancer: results from the Childhood Cancer Survivor Study. Am J Hematol Oncol 2009;8:492-3.

55. Mueller BA, Chow EJ, Kamineni A, et al. Pregnancy outcomes in female childhood and adolescent cancer survivors: a linked cancer-birth registry analysis. Arch Pediatr Adolesc Med 2009;163:879-86.

56. Chow EJ, Kamineni A, Daling JR, et al. Reproductive outcomes in male childhood cancer survivors: a linked cancer-birth registry analysis. Arch Pediatr Adolesc Med 2009;163:887-94.

57. Goodwin T, Oosterhuis BE, Kiernan M, Hudson MM, Dahl GV. Attitudes and practices of pediatric oncology providers regarding fertility issues. Pediatr Blood Cancer 2007;48:80-5.

58. Quinn GP, Vadaparampil ST, Lee J-H, et al. Physician referral for fertility preservation in oncology patients: a national study of practice behaviors. J Clin Oncol 2009;27:5952-7.

59. Mertens AC. Cause of mortality in 5-year survivors of childhood cancer. Pediatr Blood Cancer 2007;48: 723-6.

60. MacArthur AC, Spinelli JJ, Rogers PC, Goddard KJ, Phillips N, McBride ML. Risk of a second malignant neoplasm among 5-year survivors of cancer in childhood and adolescence in British Columbia, Canada. Pediatr Blood Cancer 2007;48:453-9.

61. Lawless SCW, Verma P, Green DM, Mahoney MC. Mortality experiences among 15+ year survivors of childhood and adolescent cancers. Pediatr Blood Cancer 2007;48:333-8.

62. Oeffinger KC, Bhatia S. Second primary cancers in survivors of childhood cancer. Lancet 2009;374:1484-5.

63. Hijiya N, Hudson MM, Lensing S, et al. Cumulative incidence of secondary neoplasms as a first event after childhood acute lymphoblastic leukemia. JAMA 2007;297:1207-15.

64. Olson JH, Möller T, Anderson H, et al. Lifelong cancer incidence in 47,697 patients treated for childhood cancer in the Nordic countries. J Natl Cancer Inst 2009;101:806-13.

65. Jenkinson HC, Hawkins MM, Stiller CA, Winter DL, Marsden HB, Stevens MC. Long-term population-based risks of second malignant neoplasms after childhood cancer in Britain. Br J Cancer 2004;91: 1905-10.

66. Haddy TB, Mosher RB, Dinndorf PA, Reaman GH. Second neoplasms in survivors of childhood and adolescent cancer are often treatable. J Adolesc Health 2004;34:324-9.

67. Langeveld NE, Grootenhuis MA, Voûte PA, de Haan RJ. Posttraumatic stress symptoms in adult survivors of childhood cancer. Pediatr Blood Cancer 2004;42:604-10.

68. Recklitis CJ, Diller LR, Li X, Najita J, Robison LL, Zeltzer L. Suicide ideation in adult survivors of childhood cancer: a report from the Childhood Cancer Survivor Study. J Clin Oncol 2010;28:655-61.

69. Pang JW, Friedman DL, Whitton JA, et al. Employment status among adult survivors in the Childhood Cancer Survivor Study. Pediatr Blood Cancer 2008; 50:104-10.

70. Janson C, Leisenring W, Cox C, et al. Predictors of marriage and divorce in adult survivors of childhood cancers: a report from the Childhood Cancer Survivor Study. Cancer Epidemiol Biomarkers Prev 2009; 18:2626-35.

71. Oeffinger KC, Hudson MM, Landier W. Survivorship: childhood cancer survivors. Prim Care 2009; 36:743-80. 